\title{
Pendidikan Inklusif Murid Berkeperluan Khas Kategori Autisme di Sekolah Rendah: Perspektif Ibu Bapa
}

\section{(Inclusive Education for Primary School Autism Students: Parents' Perspectives)}

\author{
Nurul Ain binti Badrul Hisam ${ }^{1}$ (D), Khairul Farhah Khairuddin²*iD \\ 1Fakulti Pendidikan, Universiti Kebangsaan Malaysia (UKM), 43600, Bangi, Selangor, Malaysia. \\ Email: ainsyam2@gmail.com \\ ${ }^{2}$ Fakulti Pendidikan, Universiti Kebangsaan Malaysia (UKM), 43600, Bangi, Selangor, Malaysia. \\ Email: kfk@ukm.edu.my
}

\section{KATA KUNCI: \\ Pendidikan inklusif \\ Autisme \\ Perspektif ibu bapa \\ Pengetahuan \\ Jangkaan}

\section{KEYWORDS:}

Inclusive education

Autism spectrum disorder

Parents' perspective

Knowledge

Expectation

\section{CORRESPONDING}

AUTHOR (*):

Khairul Farhah Khairuddin

(kfk@ukm.edu.my)

\section{CITATION:}

Nurul Ain Badrul Hisam \& Khairul Farhah Khairuddin. (2022). Pendidikan Inklusif Murid Berkeperluan Khas Kategori Autisme di Sekolah Rendah: Perspektif Ibu Bapa. Malaysian Journal of Social Sciences and Humanities (MJSSH), 7(2), e001286.

https://doi.org/10.47405/mjssh.v7i2.1286

\begin{abstract}
ABSTRAK
Perspektif ibu bapa dalam perlaksanaan Program Pendidikan Inklusif (PPI) di sekolah rendah merupakan usaha berpusatkan keluarga yang digunakan di peringkat global sebagai salah satu strategi penentu kejayaan PPI. Kajian ini mengenai perspektif ibu bapa dari aspek pengetahuan dan jangkaan. Kajian ini dijalankan bertujuan mengenal pasti tahap pengetahuan dan tahap jangkaan ibu bapa murid autisme di sekolah rendah terhadap pendidikan inklusif. Pendekatan kuantitatif telah dipilih dengan menggunakan reka bentuk kajian tinjauan. Seramai 54 orang responden sekitar Langkawi, Kedah telah dipilih secara persampelan rawak mudah menjawab edaran soal selidik dalam bentuk Google Form. Maklum balas yang diberikan oleh responden dianalisis secara deskriptif. Analisis deskriptif dalam kajian ini melibatkan kekerapan, peratusan dan min. Perisian Statistical Package for Social Science (SPSS) versi 26 juga digunakan untuk memproses dapatan. Hasil dapatan kajian menunjukkan min bagi tahap pengetahuan $(\mathrm{min}=3.63)$ dan tahap jangkaan $(\min =3.06)$ ibu bapa berada di tahap yang sederhana. Kesimpulannya, ibu bapa masih memerlukan panduan dan bimbingan daripada pemegang taruh pelbagai disiplin. Informasi yang komprehensif dapat membantu mereka memahami kesan terhadap keputusan yang dibuat.
\end{abstract}

\section{ABSTRACT}

Parent empowerment in the implementation of the Inclusive Education Programme (PPI) in primary schools is a familycentered effort used globally as one of the PPI success determining strategies. This study is about the perspective of parents in terms of knowledge and expectations. The study was aimed at identifying the level of knowledge and expectation levels of parents' with Autism students in primary schools towards inclusive education. A quantitative approach was chosen using the design of the survey study. A 
total of 54 respondents around Langkawi, Kedah were selected for random sampling to easily answer the distribution of questionnaires in the form of Google Form. The feedback given by the respondents was descriptively analyzed. Descriptive analysis in this study involved frequency, percentage, mean and standard deviation. The Statistical Package for Social Science (SPSS) version 26 is also used to process findings. The findings showed that the mean for knowledge level (mean $=3.63$ ) and expectation level (mean $=3.06$ ) of parents were at moderate levels.

Sumbangan/Keaslian: Kajian ini adalah salah satu daripada kajian yang telah mengenalpasti tahap pengetahuan dan tahap jangkaan ibu bapa terhadap pendidikan inklusif di sekolah rendah. Sumbangan utama kajian ini ialah mendapati bahawa kajian ini memberi gambaran populasi ibu bapa sekitar daerah Langkawi, Kedah yang merupakan demografi penduduk yang tinggal di kepulauan.

\section{Pengenalan}

Matlamat Pembangunan Mampan (Sustainable Developmental Goal - SDG) yang keempat memberi penekanan khusus kepada kualiti pendidikan. Pendidikan inklusif merupakan salah satu usaha perlaksanaan yang tidak terkecuali untuk dinilai sebagai agenda pembangunan sejagat. Namun begitu, dalam penilaian kualiti pendidikan di peringkat antarabangsa, krisis pendidikan berlaku di serata dunia untuk mencapai kualiti yang ditetapkan (UNESCO, 2017). Program Pendidikan Inklusif dilihat sebagai salah satu strategi berkesan untuk menangani krisis pendidikan berkaitan isu diskriminasi pendidikan yang bertentangan dengan konsep Pendidikan Untuk Semua (EFA) (Kementerian Pendidikan Malaysia, 2018). Pendidikan inklusif merupakan perjuangan hak asasi manusia tanpa mengira jantina, bangsa, latar belakang dan keupayaan individu secara menyeluruh dalam kehidupan (United Nations, 2016). Polisi pendidikan inklusif telah banyak dibincangkan secara meluas di Eropah sebelum diguna pakai di Asia Tenggara termasuklah Malaysia.

Perlaksanaan Program Pendidikan Inklusif di Malaysia merujuk kepada Garis Panduan Program Pendidikan Inklusif Murid Berkeperluan Khas edisi 2018, Modul Latihan Pembangunan Profesionalisme Guru (Pendidikan Inklusif) dan Modul Ibu Bapa Program Pendidikan Inklusif. Dasar Pendidikan Inklusif turut diwujudkan bagi memberi penekanan terhadap peningkatan akses pendidikan murid berkeperluan khas untuk turut sama berdaya saing bersama murid arus perdana dalam bilik darjah yang sama, sama ada di sekolah kerajaan mahupun sekolah bantuan kerajaan selari dengan Pelan Pembangunan Pendidikan Malaysia (PPPM) 2013-2025. Platform pendidikan inklusif ini diwujudkan bagi memastikan hasrat kerajaan ini dapat dilaksanakan dengan jayanya secara berterusan.

Kementerian Pendidikan Malaysia menyasarkan 75 peratus murid berkeperluan khas (MBK) akan mendaftar dalam program pendidikan inklusif menjelang tahun 2025 (Amin, 2019). Selain itu, dalam PPPM 2013-2025 turut meletakkan sasaran bekerjasama dengan ibu bapa pada Anjakan 9. Dalam Anjakan 9 ini, transformasi sistem pendidikan dapat dilakukan secara berkesan dengan memberi maklumat kepada ibu bapa bagi membantu pembelajaran anak mereka melalui sarana penglibatan ibu bapa dan akses atas talian terhadap kemajuan anak di sekolah. 


\section{Sorotan Literatur}

Pendidikan inklusif dilihat mengandungi satu set nilai, tujuan, andaian yang unik dan mencabar idea-idea yang dianggap relevan untuk mendidik kanak-kanak berkeperluan khas (Paseka \& Schwab, 2020). Oleh itu, ibu bapa berpendapat idea pendidikan inklusif dilihat relevan untuk memenuhi keperluan pendidikan murid berkeperluan khas (Wilson et al., 2017). Penglibatan keluarga di sekolah adalah satu cara untuk membina kepercayaan, rasa hormat dan membuka komunikasi dua hala antara guru dan ibu bapa. Faktor utama yang menyumbang secara positif kepada pendidikan inklusif di seluruh dunia adalah peranan advokasi yang dimainkan oleh keluarga murid berkeperluan khas, terutamanya, usaha mereka menempatkan anak-anak dalam pendidikan arus perdana (Afolabi, 2014). Ibu bapa yang berpengalaman dalam advokasi pendidikan anak-anak ialah mereka yang mengambil bahagian dan terlibat secara aktif dalam aktiviti sekolah berfokuskan perkembangan sosiokognitif dan prestasi murid (Epstein \& Voorhis, 2001). Namun begitu, kurangnya penglibatan ibu bapa dalam memberikan pandangan dilihat sebagai ibu bapa kurang menyertai aktiviti sekolah (Stahmer et al., 2019).

Ibu bapa murid berkeperluan khas menghadapi masalah untuk menentukan penempatan yang sesuai dengan keupayaan anak-anak mereka (Ratliff-Black \& Therrien, 2021). Dalam senario lain, segelintir ibu bapa yang tidak hadir perjumpaan Rancangan Pendidikan Individu (RPI) dilihat tidak berpeluang berbincang mengenai perkembangan anak berkeperluan khas mereka (Kurth et al., 2020). Persepsi ibu bapa terhadap pendidikan inklusif bergantung kepada tahap ketidakupayaan anak, usia anak dan bilangan tahun anak berada di pendidikan arus perdana (Leyser \& Kirk, 2004).

Perlaksanaan pendidikan inklusif turut melibatkan stigma dan pandangan masyarakat sekolah terutamanya. Stigma budaya penerimaan negatif dalam kalangan masyarakat merupakan model sosial yang sinonim dengan situasi berat sebelah dan layanan tidak adil yang diberikan kepada individu kurang upaya (Devlieger, 2005). Dari sudut pandang budaya, kecacatan bukanlah nasib individu atau semata-mata akibat diskriminasi dan pengecualian. Sebaliknya, kemerosotan dan kecacatan yang dilabelkan merupakan hasil daripada pengetahuan yang cetek dan usaha yang sedikit untuk membantu individu kurang upaya ini menjalani kehidupan dalam rutin yang hampir sama dengan individu yang lain (Brydges \& Mkandawire, 2017).

\section{Metod Kajian}

Kajian ini merupakan kajian tinjauan menggunakan pendekatan kuantitatif. Instrumen soal selidik diedarkan secara dalam talian melalui aplikasi Google Form. Pembinaan soal selidik tidak melibatkan kos yang tinggi dan menjimatkan masa untuk proses pengutipan data (Gillham, 2008). Di samping itu, soal selidik merupakan alat tinjauan yang sangat berguna yang membolehkan populasi besar dinilai dengan mudah (Jones, 2013). Seramai 54 orang responden telah dipilih melalui persampelan rawak mudah di sekitar Langkawi, Kedah. Sebelum soalan soal selidik diedarkan, kajian ini telah mendapat kelulusan bersyarat daripada Bahagian Perancangan dan Penyelidikan Dasar Pendidikan (BPPDP), KPM melalui laman sesawang ERAS 2.0. Kajian ini juga turut mendapat kebenaran menjalankan kajian daripada Jabatan Pendidikan Negeri Kedah dan Pejabat Pelajaran Daerah Langkawi. Soal selidik yang dibangunkan merupakan adaptasi daripada soalan Inclusive Classroom Profile (Soukakou et al., 2018) dan Parents Attitude Towards Inclusion (Palmer et al., 2001). Kesahan muka telah dilakukan bersama pensyarah penyelia 
berkenaan instrumen soal selidik yang digunakan dan kesahan bahasa dilakukan bersama guru Bahasa Inggeris di sekolah. Kajian rintis telah dijalankan oleh pembangun asal instrumen.

Instrumen soal selidik ini telah membentuk kriteria penilaian ibu bapa. Instrumen ini menggunakan skala Likert lima pilihan. Secara dasarnya, instrumen ini digunakan untuk melihat pandangan ibu bapa terhadap kelas inklusif yang kondusif di sekolah. Dalam soal selidik ini, kaedah reversed-score digunakan bagi meningkatkan kebolehpercayaan jawapan soal selidik daripada sampel kajian. Soal selidik ini terdiri daripada 5 bahagian. Perincian instrumen soal selidik adalah seperti dalam Jadual 1.

Jadual 1: Instrumen Kajian

\begin{tabular}{lll}
\hline Bahagian & Konstruk & Bilangan Item \\
\hline A & Maklumat Demografi & 12 \\
B & Aspek Pengetahuan Ibu Bapa & 12 \\
C & Aspek Jangkaan Ibu Bapa & 11 \\
D & Cadangan Ibu Bapa Berkenaan Program Pendidikan Inklusif & 1 \\
& MBK Kategori Autisme Sekolah Rendah & \\
& (Soalan Respon Terbuka) & 1 \\
E & $\begin{array}{l}\text { Harapan Ibu Bapa Berkenaan Program Pendidikan Inklusif } \\
\text { MBK Kategori Autisme Sekolah Rendah (Soalan Respon } \\
\end{array}$ & \\
\hline
\end{tabular}

Kajian ini melibatkan analisis deskriptif. Analisis deskriptif dalam kajian ini melibatkan kekerapan, peratusan dan min. Interpretasi tahap bagi min untuk tahap pengetahuan dan tahap jangkaan ibu bapa ditentukan dalam tiga tahap. Jadual 2 menunjukkan interpretasi tahap min bagi pengetahuan dan jangkaan ibu bapa.

Jadual 2: Interpretasi Min Bagi Pengetahuan dan Jangkaan Ibu Bapa

\begin{tabular}{ll}
\hline Skor $\min$ & Interpretasi \\
\hline $1.00-2.33$ & Rendah \\
$2.34-3.67$ & Sederhana \\
$3.68-5.00$ & Tinggi \\
\hline
\end{tabular}

Sumber : Wiersma (1995)

\section{Hasil Kajian}

\subsection{Maklumat Demografi Responden}

Berdasarkan analisis profil demografi terhadap 54 orang responden, didapati 45 orang $(83.3 \%)$ jantina perempuan manakala 9 orang $(16.7 \%)$ terdiri daripada lelaki. Bagi kategori umur pula, lingkungan umur 30 hingga 39 tahun merupakan responden dengan bilangan tertinggi seramai 33 orang (61.1\%) . Rata-rata responden berkelulusan Sijil Pelajaran Malaysia (SPM) dengan bilangan seramai 27 orang (50\%). Bagi umur murid berkeperluan khas kategori autisme, paling tinggi direkodkan bagi anak jagaan berusia 8 tahun iaitu seramai 32 orang (44.4\%). Jadual 3 menunjukkan skor peratusan mengikut kategori dan pemboleh ubah demografi dalam maklumat demografi responden. 
Jadual 3: Maklumat Demografi Responden

\begin{tabular}{lll}
\hline Pemboleh ubah Demografi & Kategori & Skor Peratusan (\%) \\
\hline Jantina & Perempuan (Ibu) & 83.3 \\
& Lelaki (Bapa) & 16.7 \\
\hline Umur & $20-29$ tahun & 11.1 \\
& 30-39 tahun & 61.1 \\
& $40-49$ tahun & 27.8 \\
\hline Tahap Pendidikan & UPSR & 22.2 \\
& SPM & 50.0 \\
& Diploma & 11.1 \\
& Ijazah Sarjana Muda & 16.7 \\
& & \\
\hline Umur Murid Autisme & 7 tahun & 11.1 \\
& 8 tahun & 44.4 \\
& 9 tahun & 11.1 \\
& 10 tahun & 11.1 \\
& 11 tahun & 5.6 \\
& 12 tahun & 16.7 \\
\hline
\end{tabular}

\subsection{Tahap Pengetahuan Ibu Bapa}

Secara keseluruhan, tahap pengetahuan ibu bapa murid autisme terhadap pendidikan inklusif di sekolah rendah berada di tahap sederhana ( $\mathrm{min}=3.63)$. Item yang mencatat min tertinggi ialah rasa kekitaan dalam menjayakan pendidikan inklusif $(\mathrm{min}=3.78, \mathrm{SP}=$ 0.718) diikuti 4 item yang mempunyai skor min yang sama iaitu aspek peranan orang dewasa sebagai pembimbing aktiviti kanak-kanak ( $\min =3.67, \mathrm{SP}=0.752)$, kepentingan sokongan komunikasi ibu bapa dalam pendidikan inklusif (min=3.67, SP=0.673), kepentingan kerjasama ibu bapa bersama ahli terapis, guru serta kumpulan profesional lain ( $\min =3.67, \mathrm{SP}=0.752$ ) dan pemantauan pembelajaran anak untuk menjayakan program pendidikan inklusif ( $\mathrm{min}=3.67, \mathrm{SP}=0.673$ ). Namun begitu, dapatan kajian menunjukkan skor min terendah bagi aspek pengetahuan pada item hubungan antara guru dan anak serta hubungan ibu bapa murid lain dengan anak saya dalam perlaksanaan pendidikan inklusif ( $\min =3.44, \mathrm{SP}=0.965)$. Jadual 4 menunjukkan min mengikut item kesediaan daripada aspek pengetahuan ibu bapa MBK sekolah rendah kategori autisme terhadap pendidikan inklusif adaptasi Inclusive Classroom Profile oleh Soukakou et al. (2018).

Jadual 4: Kesediaan aspek pengetahuan ibu bapa MBK sekolah rendah kategori autisme terhadap pendidikan inklusif adaptasi Inclusive Classroom Profile

\begin{tabular}{llll}
\hline Bil & Item & Min & SP \\
\hline 1 & Kepentingan ruang dan kemudahan peralatan & 3.56 & 0.769 \\
2 & Penglibatan ibu bapa dalam interaksi rakan sebaya & 3.61 & 0.763 \\
3 & Peranan orang dewasa sebagai pembimbing aktiviti bermain kanak- & 3.67 & 0.752 \\
& kanak & 3.61 & 0.763 \\
4 & Penyelesaian konflik dalam interaksi antara murid & 3.78 & 0.718 \\
5 & Rasa kekitaan dalam menjayakan pendidikan inklusif & 3.44 & 0.965 \\
6 & $\begin{array}{l}\text { Hubungan antara guru dan anak serta hubungan ibu bapa murid lain } \\
\text { dengan anak saya dalam perlaksanaan pendidikan inklusif }\end{array}$ & 3.67 & 0.673 \\
7 & $\begin{array}{l}\text { Kepentingan sokongan komunikasi ibu bapa dalam pendidikan } \\
\text { inklusif }\end{array}$ & 3.50 & 0.906
\end{tabular}


Setiap aktiviti yang dilakukan bersama anak di sekolah mempunyai

3.610 .899 perubahan mengikut keupayaan anak..

10 Keperluan maklum balas ibu bapa terhadap program pendidikan

$3.72 \quad 0.738$ inklusif.

11 Kepentingan kerjasama ibu bapa bersama ahli terapis, guru serta kumpulan profesional lain.

12 Pemantauan pembelajaran anak untuk menjayakan program

$3.67 \quad 0.673$ pendidikan inklusif

\subsection{Tahap Jangkaan Ibu Bapa}

Bagi aspek ini, hasil dapatan kajian secara keseluruhannya menunjukkan tahap jangkaan ibu bapa murid autisme terhadap pendidikan inklusif di sekolah rendah berada di tahap yang sederhana ( $\min =3.06$ ). Jangkaan ibu bapa terhadap pendidikan inklusif mampu mewujudkan persahabatan antara murid berkeperluan khas dengan rakan aliran perdana mempunyai skor min paling tinggi $(\min =3.33$, SP=0.673). Skor min paling rendah dicatatkan ialah pada item pendidikan inklusif meningkatkan kualiti pendidikan murid berkeperluan khas $(\min =2.72, \mathrm{SP}=0.940$ ) dan pendidikan inklusif menyebabkan berlakunya layanan buruk daripada rakan sebaya (min=2.72, SP=0.878). Ini menunjukkan ibu bapa kebanyakan kurang bersetuju dengan jangkaan menurut keduadua item ini. Jadual 5 menunjukkan min mengikut item kesediaan daripada aspek jangkaan ibu bapa MBK sekolah rendah kategori autisme terhadap pendidikan inklusif adaptasi soal selidik Parents' Attitude Towards Inclusion oleh Palmer et al. (2001).

Jadual 5: Kesediaan aspek jangkaan ibu bapa MBK sekolah rendah kategori autisme terhadap pendidikan inklusif adaptasi Parents' Attitude Towards Inclusion

\begin{tabular}{|c|c|c|c|}
\hline Bil & Item & Min & SP \\
\hline 1 & Pendidikan inklusif meningkatkan kualiti pendidikan MBK & 2.72 & 0.940 \\
\hline 2 & $\begin{array}{l}\text { Pendidikan inklusif menyebabkan layanan buruk rakan aliran } \\
\text { perdana }\end{array}$ & 2.72 & 0.878 \\
\hline 3 & $\begin{array}{l}\text { Pendidikan inklusif menyebabkan anak disisihkan rakan aliran } \\
\text { perdana }\end{array}$ & 3.17 & 0.841 \\
\hline 4 & $\begin{array}{l}\text { Pendidikan inklusif memberikan manfaat lebih baik untuk keadaan } \\
\text { MBK }\end{array}$ & 2.78 & 1.040 \\
\hline 5 & $\begin{array}{l}\text { Hubungan antara guru dan anak serta hubungan ibu bapa murid lain } \\
\text { dengan anak saya dalam perlaksanaan pendidikan inklusif }\end{array}$ & 3.06 & 0.712 \\
\hline 6 & $\begin{array}{l}\text { Kepentingan sokongan komunikasi ibu bapa dalam pendidikan } \\
\text { inklusif }\end{array}$ & 3.11 & 0.883 \\
\hline 7 & Aktiviti berkumpulan ketika pendidikan inklusif berlangsung & 3.33 & 0.673 \\
\hline 8 & $\begin{array}{l}\text { Setiap aktiviti yang dilakukan bersama anak di sekolah mempunyai } \\
\text { perubahan mengikut keupayaan anak }\end{array}$ & 3.11 & 0.945 \\
\hline 9 & $\begin{array}{l}\text { Keperluan maklum balas ibu bapa terhadap program pendidikan } \\
\text { inklusif }\end{array}$ & 3.28 & 0.811 \\
\hline 10 & $\begin{array}{l}\text { Kepentingan kerjasama ibu bapa bersama ahli terapis, guru serta } \\
\text { kumpulan profesional lain }\end{array}$ & 3.17 & 0.952 \\
\hline \multirow[t]{2}{*}{11} & $\begin{array}{l}\text { Pemantauan pembelajaran anak untuk menjayakan program } \\
\text { pendidikan inklusif }\end{array}$ & 3.17 & 0.607 \\
\hline & PURATA MIN KESELURUHAN & 3.06 & \\
\hline
\end{tabular}


Kekerapan jawapan ibu bapa pada konstruk "Cadangan dan Harapan" ibu bapa terhadap pendidikan inklusif di sekolah rendah turut memberikan gambaran. Tiga tema utama jawapan yang dapat dikenal pasti melalui maklum balas ibu bapa ialah kompetensi guru pendidikan khas, perlaksanaan PdP dan peranan rakan sebaya. Jadual 6 di bawah menunjukkan kekerapan berdasarkan analisis tema jawapan soalan respons terbuka.

Jadual 6: Analisis Tema Jawapan Soalan Respon Terbuka

\begin{tabular}{llll}
\hline Bil & Tema & Kekerapan & Peratusan (\%) \\
\hline 1 & Kompetensi Guru Pendidikan Khas & 19 & 35.2 \\
2 & Peranan Rakan Sebaya Arus Perdana & 6 & 11.1 \\
3 & Perlaksanaan Pengajaran dan Pembelajaran & 8 & 14.8 \\
4 & Tiada Cadangan & 10 & 18.5 \\
5 & Berpuas hati dengan keadaan sedia ada & 11 & 20.4 \\
\hline
\end{tabular}

\section{Perbincangan Kajian}

Dapatan menunjukkan tahap pengetahuan ibu bapa mengenai kepentingan ruang dan kemudahan peralatan berada di tahap sederhana $(\min =3.56, \mathrm{SP}=0.769)$. Ini menunjukkan kebanyakan ibu bapa tidak begitu memahami persekitaran fizikal turut memainkan peranan penting dalam implementasi pendidikan inklusif. Hal ini disokong dalam kajian lepas bahawa pendekatan berdasarkan keupayaan mengukur kualiti hidup dengan penekanan yang besar terhadap kebebasan membina potensi diri dalam persekitaran sekelilingnya (Lim, 2020). Oleh itu, ekologi pendidikan inklusif perlu disemak dan dinilai sama ada persekitaran tersebut menyokong keupayaan individu untuk menyerlahkan potensi masing-masing terutamanya dalam konteks sekolah rendah. Ekologi pendidikan yang baik akan meningkatkan penglibatan aktif murid kerana autonomi yang diberikan dalam ruang lebih selesa dn menggalakkan strategi untuk perkembangan regulasi kendiri (Martínez-Rodríguez \& Benítez-Corona, 2020).

Reka bentuk persekitaran inklusif perlu dibincangkan dan ibu bapa wajar diberi taklimat mengenai hal ini. The European Institute for Design and Disability (EIDD) melihat reka bentuk persekitaran inklusif turut melibatkan reka bentuk yang meraikan kepelbagaian individu, penglibatan sosial dan kesamarataan (Heylighen et al., 2017). Dalam erti kata mudah, reka bentuk persekitaran inklusif yang diwujudkan perlu mudah diakses, mudah digunakan semua lapisan golongan masyarakat dan mengikut kesesuaian keupayaan individu untuk memberi respons kepada persekitaran yang disediakan. Halangan yang wujud dalam struktur persekitaran fizikal inklusif akan memberi kesan yang buruk kepada penglibatan murid berkeperluan khas dalam kelas arus perdana (Craig \& Kukendall, 2020).

Seterusnya, dapat disimpulkan bahawa ibu bapa lebih cenderung bersetuju bahawa persahabatan antara murid berkeperluan khas bersama rakan sebaya dalam pendidikan inklusif memainkan peranan penting. Hal ini dapat dilihat item pendidikan inklusif mewujudkan persahabatan bersama rakan sebaya mempunyai skor min yang paling tinggi dibandingkan dengan item yang lain ( $\min =3.33$ ). Impak kewujudan stigma dan kurangnya sokongan rakan sebaya dapat dilihat apabila murid berkeperluan khas diasingkan di dalam kelas pendidikan khas manakala murid biasa ditempatkan dalam kelas arus perdana (Lim, 2020). Hal ini turut disokong dengan 6 orang responden memberi jawapan pada soalan respons terbuka peranan rakan sebaya dalam kelas arus perdana sebagai cadangan dan harapan. 
Hakikatnya, sistem sekolah yang mengklasifikasikan murid mengikut keupayaan merupakan satu langkah efektif untuk mengenal pasti dan memberitahu ahli komuniti sekolah yang lain, ada golongan yang perlu diberi perhatian khusus dan dibantu dengan sumber tambahan bagi menjalani pembelajaran yang berkesan di sekolah. Namun begitu, persamaan ciri lain antara murid berkeperluan khas dengan murid arus perdana perlu dinyatakan dengan jelas agar stigma tidak wujud untuk membezakan kedua-dua murid ini di sekolah dalam persepsi negatif (Terzi, 2014). Persamaan yang boleh dilakukan ialah dari segi cara berpakaian dengan memakai uniform sekolah yang sama, berkongsi ruang kemudahan yang sama seperti kantin dan surau serta berada dalam kawasan sekolah yang sama.

Model sosial-relasional boleh digunakan untuk membantu menerangkan kepada ibu bapa cadangan sokongan rakan sebaya dalam perlaksanaan pendidikan inklusif. Hal ini kerana model ini dapat mengubah pandangan mengenai perbezaan dalam kepelbagaian individu dengan lebih baik melalui pendekatan berasaskan keupayaan (Sen, 1992). Model ini mampu membantu advokasi kesamarataan dalam pendidikan dan tambahan kepada sokongan terhadap sumber bagi memastikan murid berkeperluan khas menerima pendidikan yang berkualiti serta haknya tidak dinafikan. Persekitaran bilik darjah yang mesra pembelajaran berasaskan model ini menjadi tempat ideal untuk murid mengembangkan kemahiran sosial seterusnya memberi impak positif pada perkembangan akademik dan emosi murid (De Pedro et al., 2016).

\section{Kesimpulan}

Kesimpulannya, perspektif ibu bapa murid autisme terhadap pendidikan inklusif di sekolah rendah berada di tahap yang sederhana berdasarkan tahap pengetahuan dan jangkaan ibu bapa. Oleh itu, cadangan tindakan seterusnya untuk ibu bapa supaya modul ibu bapa bagi Program Pendidikan Inklusif perlu diberi taklimat dan disebarluaskan. Modul ibu bapa ini telah diwujudkan sejak 2018. Hal ini kerana, dengan pengenalan modul ibu bapa, ibu bapa dapat menerima maklumat dengan sistematik mengikut keperluan, mengurangkan stres dalam kalangan ibu bapa sepanjang carian maklumat dilakukan dan penerimaan ibu bapa terhadap potensi murid berkeperluan khas kategori autisme terutamanya dapat ditingkatkan (Patra et al., 2015). Kesimpulannya, ibu bapa masih memerlukan panduan dan bimbingan daripada pemegang taruh pelbagai disiplin. Informasi yang komprehensif dapat membantu mereka memahami kesan terhadap keputusan yang dibuat.

\section{Penghargaan (Acknowledgement)}

Penghargaan kepada responden yang telah memberikan kerjasama dalam menjayakan kajian ini. Kerjasama yang diberikan responden amat baik dan membantu penghasilan penulisan kajian dari segi dapatan kajian.

\section{Kewangan (Funding)}

Kajian dan penerbitan ini tidak menerima sebarang tajaan atau bantuan kewangan daripada mana-mana pihak. 


\section{Konflik Kepentingan (Conflict of Interests)}

Penulis tidak mempunyai konflik kepentingan dalam menjalankan kajian dan penerbitan artikel ini.

\section{Rujukan}

Afolabi, O. E. (2014). Parents involvement in inclusive education: An empirical test for the psycho-educational development of learners with special educational needs (SENs). International Journal of Educational Administration and Policy Studies, 6(10), 196-208.

Brydges, C., \& Mkandawire, P. (2017). Perceptions and concerns about inclusive education among students with visual impairments in Lagos, Nigeria. International Journal of Disability, Development and Education, 64(2), 211-225.

Craig, L., \& Kuykendall, L. (2020). Fostering an inclusive classroom environment with evidence-based approaches. Industrial and Organizational Psychology, 13(4), 482486.

Dawson-Squibb, J. J., Davids, E. L., Harrison, A. J., Molony, M. A., \& de Vries, P. J. (2020). Parent Education and Training for autism spectrum disorders: Scoping the evidence. Autism, 24(1), 7-25.

De Pedro, K. T., Gilreath, T., \& Berkowitz, R. (2016). A latent class analysis of school climate among middle and high school students in California public schools. Children and Youth Services Review, 63, 10-15.

Devlieger, P. J. (2005, October). Generating a cultural model of disability. In 19th Congress of the European Federation of Associations of Teachers of the Deaf (FEAPDA) (pp. 1416).

Epstein, J. L., \& Van Voorhis, F. L. (2001). More than minutes: Teachers' roles in designing homework. Educational psychologist, 36(3), 181-193.

Gillham, B. (2008). Developing a questionnaire. A\&C Black.

Heylighen, A., Van der Linden, V., \& Van Steenwinkel, I. (2017). Ten questions concerning inclusive design of the built environment. Building and environment, 114, 507-517.

Hodges, A., Joosten, A., Bourke-Taylor, H., \& Cordier, R. (2020). School participation: The shared perspectives of parents and educators of primary school students on the autism spectrum. Research in developmental disabilities, 97, 103550.

Jones, C. P. (2013). Culture and society in Lucian. Harvard University Press.

Kementerian Pendidikan Malaysia. (2018). Modul Ibu Bapa Program Pendidikan Inklusif.

Kurth, J. A., Love, H., \& Pirtle, J. (2020). Parent perspectives of their involvement in IEP development for children with autism. Focus on Autism and Other Developmental Disabilities, 35(1), 36-46.

Leyser, Y., \& Kirk, R. (2004). Evaluating inclusion: An examination of parent views and factors influencing their perspectives. International journal of disability, development and education, 51(3), 271-285.

Lim, S. (2020). The capabilities approach to inclusive education: re-envisioning the individuals with disabilities education act's least restrictive environment. Disability \& Society, 35(4), 570-588.

Martínez-Rodríguez, R. C. M. R., Benítez-Corona, L. B. C., Martínez-Rodríguez, R. C., \& Benítez-Corona, L. (2020). The ecology of resilience learning in ubiquitous environments to adverse situations. Comunicar. Media Education Research Journal, 28(1). 
Palmer, D. S., Fuller, K., Arora, T., \& Nelson, M. (2001). Taking sides: Parent views on inclusion for their children with severe disabilities. Exceptional children, 67(4), 467484.

Paseka, A., \& Schwab, S. (2020). Parents' attitudes towards inclusive education and their perceptions of inclusive teaching practices and resources. European Journal of Special Needs Education, 35(2), 254-272.

Patra, S., Arun, P., \& Chavan, B. S. (2015). Impact of psychoeducation intervention module on parents of children with autism spectrum disorders: A preliminary study. Journal of neurosciences in rural practice, 6(04), 529-535.

Ratliff-Black, M., \& Therrien, W. (2021). Parent-mediated interventions for school-age children with ASD: A meta-analysis. Focus on Autism and Other Developmental Disabilities, 36(1), 3-13.

Sen, A. (1995). Inequality reexamined. Harvard University Press.

Senin, A. (2019, 26 September. Kementerian Pendidikan sasar kemasukan MBK meningkat. Berita https://www.bharian.com.my/berita/nasional/2019/09/611224/kementerianpendidikan-sasar-kemasukan-mbk-meningkat

Shim-Pelayo, H., \& De Pedro, K. T. (2018). The role of school climate in rates of depression and suicidal ideation among school-attending foster youth in California public schools. Children and Youth Services Review, 88, 149-155.

Soukakou, E., Evangelou, M., \& Holbrooke, B. (2018). Inclusive Classroom Profile: a pilot study of its use as a professional development tool. International Journal of Inclusive Education, 22(10), 1124-1135.

Stahmer, A. C., Vejnoska, S., Iadarola, S., Straiton, D., Segovia, F. R., Luelmo, P., ... \& Kasari, C. (2019). Caregiver voices: Cross-cultural input on improving access to autism services. Journal of racial and ethnic health disparities, 6(4), 752-773.

Terzi, L. (2014). Reframing inclusive education: Educational equality as capability equality. Cambridge Journal of Education, 44(4), 479-493.

UNESCO, A. (2017). A guide for ensuring inclusion and equity in education. Geneva: UNESCO IBE. https://unesd oc. unesc o. org/ark:/48223/pf000, 2482, 54.

United Nations Committee on the Rights of Persons with Disabilities. (2016). Inquiry concerning the United Kingdom of Great Britain and Northern Ireland carried out by the committee under article 6 of the optional protocol to the convention report of the committee.

Wiersma, W. (1995). Research Methods in Education: An Introduction. Boston: Allyn and Bacon.

Wilson, N. J., Jaques, H., Johnson, A., \& Brotherton, M. L. (2017). From social exclusion to supported inclusion: Adults with intellectual disability discuss their lived experiences of a structured social group. Journal of Applied Research in Intellectual Disabilities, 30(5), 847-858. 